\title{
Familial aggregation of cluster headache
}

\author{
Agregação familiar da cefaleia em salvas \\ Simão Cruz', Carolina Lemos², José Maria Pereira Monteiro ${ }^{3}$
}

\begin{abstract}
Several studies suggest a strong familial aggregation for cluster headache $(\mathrm{CH})$, but so far none of them have included subjects with probable cluster headache $(\mathrm{PCH})$ in accordance with the International Classification of Headache Disorders. Objective: To identify cases of probable cluster headache and to assess the familial aggregation of cluster headache by including these subjects. Method: Thirty-six patients attending a headache consultation and diagnosed with trigeminal autonomic headaches were subjected to a questionnaire-based interview. A telephone interview was also applied to all the relatives who were pointed out as possibly affected as well as to some of the remaining relatives. Results: Twenty-four probands fulfilled the criteria for $\mathrm{CH}$ or PCH; they had 142 first-degree relatives, of whom five were found to have $\mathrm{CH}$ or $\mathrm{PCH}$, including one case of $\mathrm{CH}$ sine headache. The risk for first-degree relatives was observed to be increased by 35- to 46-fold. Conclusion: Our results suggest a familial aggregation of cluster headache in the Portuguese population.
\end{abstract}

Keywords: cluster headache, probable cluster headache, familial aggregation, cluster headache sine headache, first-degree relatives.

\section{RESUMO}

Diversos artigos sugerem uma significativa agregação familiar da cefaleia em salvas $(\mathrm{CH})$ embora nenhum tenha incluído indivíduos com provável cefaleia em salvas (PCH), segundo critérios da Classificação Internacional de Cefaleias (ICHD-II). Objetivo: Encontrar casos de provável cefaleia em salvas e avaliar a agregação familiar da cefaleia em salvas incluindo também esses indivíduos. Método: Foi aplicado um questionário por telefone a 36 doentes que frequentaram uma Consulta de Cefaleias com diagnóstico de cefaleia trigémino-autonómica. Todos os familiares de primeiro grau referidos como possivelmente afetados e alguns dos restantes foram entrevistados por telefone. Resultados: Em 24 doentes foi diagnosticada $\mathrm{CH}$ ou PCH e estes tinham 142 familiares de primeiro grau, cinco dos quais foram diagnosticados como $\mathrm{CH}$ ou PCH, incluindo um caso de $\mathrm{CH}$ sem cefaleias. O risco para familiares de primeiro grau foi 35-46 vezes superior ao da população geral. Conclusão: Nossos resultados sugerem a existência de uma agregação familiar da cefaleia em salvas na população portuguesa.

Palavras-chave: cefaleia em salvas, provável cefaleia em salvas, agregação familiar, cefaleia em salvas sem cefaleia, familiares de primeiro grau.

Cluster headache $(\mathrm{CH})$ is a form of trigeminal autonomic headache defined by a set of criteria that include a severe, unilateral pain, usually located around the orbit, combined with disautonomic manifestations affecting the same region, and usually accompanying the pain ${ }^{1}$. The International Classification of Headache Disorders (ICHD-II) also recognizes the concept of probable cluster headache $(\mathrm{PCH})$, which requires the fulfillment of all $\mathrm{CH}$ criteria but one. Cases presenting with these "incomplete" forms have already been reported, and in some of these, a conversion into a "complete" form or vice-versa has occurred ${ }^{2,3}$. The estimate for the prevalence of $\mathrm{CH}$ among the general population ranges from 56 to 401 per 100.000 ${ }^{4-11}$. A Portuguese population-based study found one individual with $\mathrm{CH}$ and one case of $\mathrm{PCH}$ among a sample of 2008 subjects $^{12}$.

Familial aggregation of this disease has been the subject of at least four studies; the results have suggested an increased risk for first-degree relatives ranging from 14- to 45-fold when compared to the general population ${ }^{13-16}$. These studies included only the patients and relatives fulfilling the complete set of criteria for $\mathrm{CH}$.

Based on the results of this study the following hypothesis emerged: if both $\mathrm{CH}$ and $\mathrm{PCH}$ cases were included, a stronger

${ }^{1}$ Serviço de Neurologia, Hospital Prof. Dr. Fernando Fonseca, Amadora/Sintra, Portugal;

${ }^{2}$ UnIGENe, Instituto de Biologia Molecular e Celular, Universidade do Porto, Portugal; ICBAS, Instituto Ciências Biomédicas Abel Salazar, Universidade do Porto, Portugal;

${ }^{3}$ Serviço de Neurologia, CHP- HSA, Centro Hospitalar do Porto, Hospital de Santo António, Porto, Portugal; ICBAS, Instituto Ciências Biomédicas Abel Salazar, Universidade do Porto, Porto, Portugal.

Correspondence: Simão Cruz; Serviço de Neurologia / Hospital Prof. Doutor Fernando Fonseca; IC 19; 2720-276 Amadora - Portugal;

E-mail:simao_cruz13@hotmail.com

Conflict of interest: There is no conflict of interest to declare.

Received 08 February 2013; Received in final form 07 June 2013; Accepted 14 June 2013. 
familial aggregation could be determined. Such findings would probably contribute to strengthening the interest in finding possible genetic factors implied in the pathogenesis of this disease.

The main objectives of this study were to find cases of $\mathrm{PCH}$ including $\mathrm{CH}$ sine headache among relatives and to evaluate the familial aggregation of a broader spectrum of $\mathrm{CH}$ in a sample of the Portuguese population.

\section{METHOD}

\section{Patient's selection}

From the population evaluated in the Outpatient Headache Clinic of Hospital Santo António (Porto, Portugal) during the last 15 years, 77 consecutive and unrelated patients suspected of having a trigeminal autonomic headache were selected.

\section{Data collection}

The first step was to contact the patients in order to evaluate a structured questionnaire to allow the fulfillment of the diagnostic criteria for $\mathrm{CH}$. The contact was made by telephone and during the contact the patients were asked if their first-degree relatives (parents, siblings, and offspring) have ever had a headache similar to their own or, alternatively, if their relatives have ever experienced paroxisms of disautonomic features compatible with $\mathrm{CH}$, even in the absence of the headache itself. Finally, the telephone number of the firstdegree relatives was requested. The second stage of this study consisted of interviewing the first-degree relatives to screen them for recurrent headaches and, in case of a positive finding, to try to match the symptoms with the diagnostic criteria for $\mathrm{CH}$. The deceased relatives referred by the probands as suspects were not considered as such. Only 12 of the relatives not considered suspects were available for interview. None of the 20 interviewed relatives were observed and examined by a neurologist. Therefore, possible secondary causes for their symptoms were not excluded.

\section{Familial aggregation}

Evaluation of $\mathrm{CH}$ familial aggregation was based on the concept of relative risk (RR), which was calculated from the ratio between the likelihood of having an affected relative considering an affected patient, and the likelihood of having a random affected individual in the general population. The latter corresponds to the prevalence of the disease among the general population. For this purpose, the estimation obtained from a Portuguese population-based study ${ }^{12}$ was used. RR was statistically determined using a univariate analysis for categorical variables ( $\chi^{2}$ test). The level of significance was set at $95 \%$ and familial aggregation was considered if the RR was greater than one.

\section{Ethical issues}

A letter containing the necessary information about this study was sent to all of the 77 patients. The Ethics Committee of Hospital Santo António approved the project.

\section{RESULTS}

It was not possible to obtain any response from 41 of the initial 77 patients due to several reasons such as death (2), refusal to collaborate (6), and incorrect contact details (33). Of the 36 subjects interviewed, 7 were excluded because their headache did not satisfy the criteria for any of the trigeminal autonomic headaches. The remaining 29 patients were classified as follows: 22 as having $\mathrm{CH}$ ( $82 \%$ with an episodic pattern and $18 \%$ with chronic $\mathrm{CH}$ ), 2 as $\mathrm{PCH}$ and 5 as short-lasting unilateral neuralgiform headache attacks with conjunctival injection and tearing (SUNCT). Only the 24 patients with $\mathrm{CH}$ or $\mathrm{PCH}$ were considered in the subsequent statistical analysis. Seventy-nine percent of these patients were male (Table 1), and the mean age of onset was 34 years (standard deviation: 15,39), ranging from 11 to 70 years.

The 24 probands with $\mathrm{CH}$ or $\mathrm{PCH}$ had a total of 142 firstdegree relatives. Five patients (21\%) had a positive family history, with 10 possible cases among the group of relatives. Of the 142 relatives, 20 (14\%) were interviewed, including 8 out of the 10 previously designated (the others had died). Three of these matched the criteria for $\mathrm{CH}$ and two were classified as PCH according to the ICHD-II. None of the unsuspected relatives had $\mathrm{CH}$ or PCH (Figure 1).

Two scenarios were considered when calculating the RR (Table 2). In the first scenario, for all the variables implied in the equation, both $\mathrm{CH}$ and $\mathrm{PCH}$ subjects were included. In the second scenario, only those individuals with $\mathrm{CH}$ were considered. First-degree relatives of probands with $\mathrm{CH}$ were estimated as having a 35- to 46-fold increased risk of having $\mathrm{CH}$ compared with the general population. Both values are statistically significant $(p<0.05)$.

\section{Cases among the affected families}

The five affected relatives belonged to the families of only three probands.

One of these probands was a 58-year-old female who had an episodic $\mathrm{CH}$ for 15 years. She had two sisters; one aged 56 years and the other aged 61 years. The former had

Table 1. Demographic characteristics of probands.

\begin{tabular}{lcccccc} 
& \multirow{2}{*}{$\begin{array}{c}\text { Number of } \\
\text { probands }(\%)\end{array}$} & \multicolumn{2}{c}{ Age } & & \multicolumn{2}{c}{ Age of onset } \\
\cline { 3 - 4 } \cline { 7 - 8 } & 24 & Mean & Range & & Mean & Range \\
\hline Total & $19(79)$ & 51 & $18-76$ & & 34 & $11-70$ \\
Male & $5(21)$ & 59 & $18-76$ & & 31 & $11-65$ \\
Female & 56 & $44-74$ & & 43 & $17-70$ \\
\hline
\end{tabular}


symptoms for 30 years, fulfilling all the criteria for $\mathrm{CH}$ except for the duration: she mentioned periods of pain lasting between 2 and 3 days. The second sister seemed to be a case of $\mathrm{CH}$ sine headache. She denied recurrent headaches, but described several episodes lasting about $30 \mathrm{~min}$, during which she complained of conjunctival injection, tearing, and ptosis exclusively affecting the left eye, without any apparent precipitant. The proband mentioned that their mother displayed similar manifestations but she had already died and was not considered as an affected relative.

The second proband was a 55-year-old male describing an episodic $\mathrm{CH}$. He had four siblings, including two males who also fulfilled all the criteria for $\mathrm{CH}$.

The third proband, a female aged 45 years, presented an episodic $\mathrm{CH}$ and had a 51-year-old brother who also fulfilled all the criteria for episodic $\mathrm{CH}$.

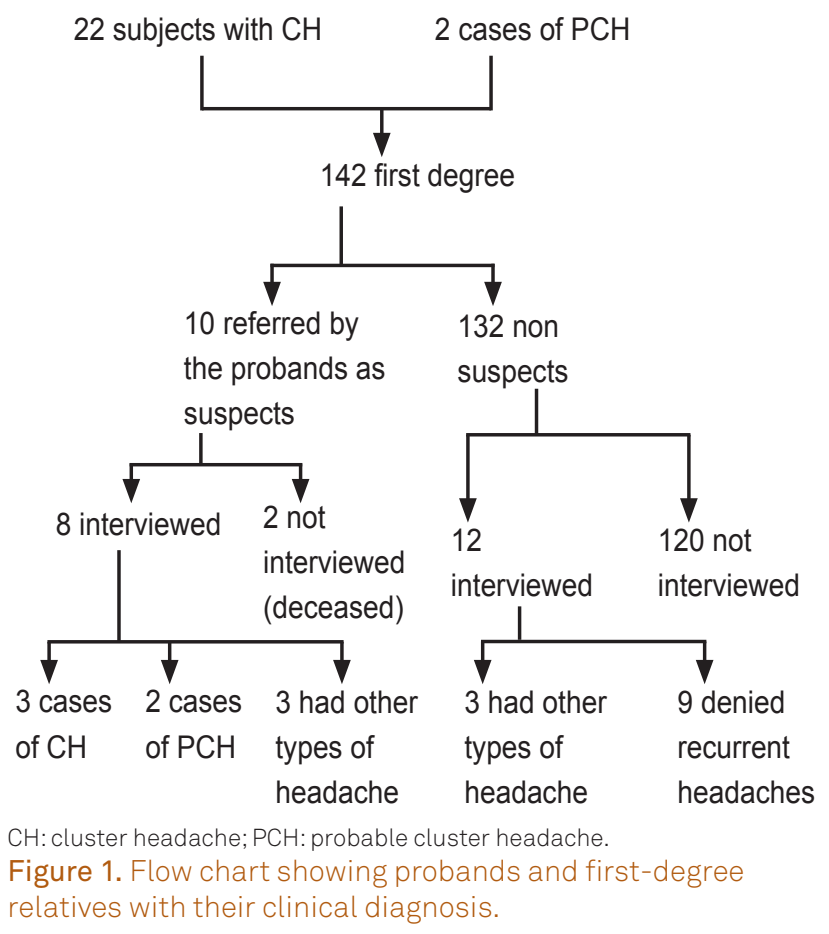

\section{DISCUSSION}

The demographic characteristics of the patients included in this study were similar to those widely reported. The male:female ratio was found to be approximately $4: 1$, thus slightly higher than that described by most authors ${ }^{17,18}$. The age of onset is also superior to what has been reported. While most patients present their first features around the third decade of life, the probands in this study had their initial symptoms about a decade later. The findings of the two patients who began complaining of $\mathrm{CH}$ symptoms at an uncommon age (11 and 70 years) are noteworthy, although similar cases have been previously reported ${ }^{19}$. The proportion of episodic and chronic patterns of $\mathrm{CH}$ in this sample (approximately 4:1) is also concordant with most studies ${ }^{20}$.

The high number of cases matching the criteria for SUNCT in this study is unexpected, as this type of headache is described as very uncommon. According to some authors, there may be some shared aspects in the physiopathology of the trigeminal autonomic headaches ${ }^{21}$. Furthermore, there are some case reports of successful usage of drugs like verapamil (most commonly used in CH) in patients with SUNCT ${ }^{22}$. While these findings may suggest some overlap between $\mathrm{CH}$ and SUCNT, it seems more likely that the exceedingly high number of cases in our study may be due to the origin of our sample (a tertiary headache clinic).

One of the most important aspects of familial aggregation studies is the choice of the prevalence estimation, because a small prevalence can lead to an overestimation of the relative risk and vice-versa. We used the data from a Portuguese population-based study ${ }^{12}$ that reported one case of $\mathrm{CH}$ and another of PCH among 2008 individuals, thus obtaining a prevalence of approximately 50/100.000, if only $\mathrm{CH}$ cases are included. This estimation is similar to those obtained in the two San Marino studies ${ }^{5,6}$ that used a thorough methodology and reported the following values: 56 and 69/100.000. Thus, the prevalence used in our study seems to be a good indicator for the prevalence of $\mathrm{CH}$ in southern Europe.

Table 2. Relative risk for first-degree relatives of patients with cluster headache and probable cluster headache.

\begin{tabular}{|c|c|c|c|c|c|c|}
\hline & & \multicolumn{3}{|c|}{ Cases included } & \multirow{2}{*}{ RR } & \multirow{2}{*}{$95 \% \mathrm{Cl}$} \\
\hline & & Prevalence & Relatives (total) & Relatives (affected) & & \\
\hline \multirow{2}{*}{ 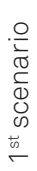 } & Condition & $\begin{array}{l}\text { To fulfill all or all but one } \\
\text { diagnostic criteria }\end{array}$ & $\begin{array}{c}\text { Should be related to a proband } \\
\text { who fulfills all or all but one } \\
\text { diagnostic criteria }\end{array}$ & $\begin{array}{l}\text { To fulfill all or all but } \\
\text { one diagnostic criteria }\end{array}$ & $35.21^{a}$ & $14.56-85.14$ \\
\hline & Value & $1: 1000$ & 142 & 5 & & \\
\hline \multirow{2}{*}{ 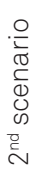 } & Condition & $\begin{array}{l}\text { To fulfill all the } \\
\text { diagnostic criteria }\end{array}$ & $\begin{array}{c}\text { Should be related to a proband } \\
\text { who fulfills all the criteria }\end{array}$ & $\begin{array}{l}\text { To fulfill all the } \\
\text { diagnostic criteria }\end{array}$ & $46.15^{a}$ & $14.58-146.09$ \\
\hline & Value & $0.5 / 1000$ & 130 & 3 & & \\
\hline
\end{tabular}

RR: relative risk; $\mathrm{Cl}$ : confidence interval.

a For both RR values, $p<0.05$. 
Considering the reports of cases presenting with $\mathrm{PCH}$ that later developed a $\mathrm{CH}^{3}$ or vice-versa ${ }^{2}$, as well as the suggestion of a broader clinical spectrum for $\mathrm{CH}$, it seemed appropriate to include individuals who present with $\mathrm{PCH}$, and not just $\mathrm{CH}$, in epidemiological studies. In our first scenario we obtained a RR of 35 and for the second a 46-fold increased risk for first-degree relatives. The difference between both values may be partially explained by the lower prevalence used in the second scenario. Thus, the hypothesis of a higher RR with the inclusion of PCH subjects was not confirmed.

The previous four published familial aggregation studies reported an increased risk for first-degree relatives ranging from approximately 14 - to 45 -fold ${ }^{13-16}$.

Both Russell et al. ${ }^{13}$, in Denmark, and Leone et al. ${ }^{14}$, in Italy, used a similar methodology and determined a RR of 14.1 and 39, respectively, for first-degree relatives. We can identify at least four important differences when comparing these studies with ours. Firstly, in these studies, only the possibly affected relatives were interviewed. Another difference has to do with the non-inclusion of PCH subjects. Furthermore, they included deceased relatives as long as the description provided by the probands was detailed enough to classify them according to ICHD. Finally, the prevalence used in these studies $(69 / 100.000)$ was only slightly higher than the one considered for our equivalent scenario (50/100.000). The samples used by these authors were far larger than ours and the confidence intervals were considerably narrower, giving an important consistency to their results.

In France, El Amrani et al. ${ }^{15}$ introduced what seems to be a methodological advantage: all first-degree relatives were directly interviewed by a neurologist. In the other studies, including ours, some affected relatives may have been lost because of a possible underreporting by the probands.

Kudrow and Kudrow ${ }^{16}$, with a North-American sample, found a RR of 45. However, the family history provided by the probands was not confirmed by a direct interview with the relatives, which may have led to an overestimation of RR.
The most important limitation of our study is the small number of subjects included, which withdraws some consistency to our results, especially when compared with similar studies. Furthermore, our sample was collected from a tertiary center, and thus a direct extrapolation for the general population cannot be done.

Only a small proportion (14\%) of the first-degree relatives was interviewed in this study and the remaining relatives were considered to be unaffected (according to the information provided by the probands). However, taking into account the possibility that there could have been some affected relatives among those not interviewed, their inclusion in the equation would have resulted in an even greater RR. Also, if this calculation was made using only the relatives who were interviewed, the RR value would have been higher. Thus, this limitation may have lead to an underestimation of the RR in this study.

Telephonic interviews have been described as a valid instrument in familial aggregation studies and prevalence studies ${ }^{23,24}$, particularly because they allow the clarification of difficult or ambiguous questions. So the use of telephone interviews seems to be an important advantage of our study. Another positive aspect is the use of a prevalence estimation obtained from a similar population.

Finally, to the best of our knowledge, our study is the first one that includes individuals with $\mathrm{PCH}$, which seems to be a major advantage given the reports of a broader spectrum for the disease. Although we have not confirmed a greater RR with this addition, our results provide significant evidence of a strong familial aggregation, thus reinforcing the theory of a genetic basis for $\mathrm{CH}$. In the future, a larger study with a similar methodology may be important to support these results.

\section{Acknowledgments}

The authors would like to thank Dr. Ângela Timóteo and Dr. José Barros for reviewing the manuscript and for their suggestions.

\section{References}

1. Olesen J, Bousser MG, Diener HC et al. The International Classification of Headache Disorders 2nd Edition (ICHD-II). International Headache Society, 2004.

2. Leone M, Rigamonti A, Bussone G. Cluster headache sine headache: two new cases in one family. Cephalalgia 2002; 22:12-14.

3. Salvesen R. Cluster headache sine headache: case report. Neurology 2000;55:451.

4. Ekbom K, Ahlborg B, Schele R. Prevalence of migraine and cluster headache in Swedish men of 18. Headache 1978;18:9-19.

5. D’Alessandro R, Gamberini G, Benassi G, Morganti G, Cortelli P, Lugaresi E. Cluster Headache in the Republic of San Marino. Cephalalgia 1986;6:159-162

6. Tonon C, Guttmann S, Volpini M, Naccarato S, Cortelli P, D’Alessandro R. Prevalence and incidence of cluster headache in the Republic of San Marino. Neurology 2002;58: 1407-1409.
7. Swanson JW, Yanagihara T, Stang PE, et al. Incidence of cluster headaches: a population-based study in Olmsted County, Minnesota. Neurology 1994;44:433-437.

8. Sjaastad O, Bakketeig LS. Cluster headache prevalence. Vaga study of headache epidemiology. Cephalalgia 2003;23:528-533.

9. Torelli P, Beghi E, Manzoni GC. Cluster headache prevalence in the Italian general population. Neurology 2005; 8;64:469-474.

10. Katsarava Z, Obermann M, Yoon MS, et al. Prevalence of cluster headache in a population-based sample in Germany. Cephalalgia 2007;27:1014-1019

11. Evers S, Fischera M, May A, Berger K. Prevalence of cluster headache in Germany: results of the epidemiological DMKG study. J Neurol Neurosurg Psychiatry 2007; 78:1289-1290.

12. Pereira Monteiro JM. Cefaleias: estudo epidemiológico e clínico de uma população urbana. Tese de doutoramento. Porto, 1995. 
13. Russell MB, Andersson PG, Thomsen LL. Familial occurrence of cluster headache. J Neurol Neurosurg Psychiatry 1995;58: 341-343.

14. Leone M, Russell MB, Rigamonti A, et al. Familial risk of cluster headache: a study of Italian families. Neurology 2001;56: 1233-1236.

15. El Amrani M, Ducros A, Boulan P, et al. Familial cluster headache: a series of 186 index patients. Headache 2002;42:974-977.

16. Kudrow L, Kudrow DB. Inheritance of cluster headache and its possible link to migraine. Headache 1994;34:400-407.

17. Ekbom K, Svensson DA, Traff H, Waldenlind E. Age at onset and sex ratio in cluster headache: observations over three decades. Cephalalgia 2002;22:94-100.

18. Manzoni GC. Male preponderance of cluster headache is progressively decreasing over the years. Headache 1997;37:588-589.
19. Evers S, Frese A, Majewski A, Albrecht O, Husstedt IW. Age of onset in cluster headache: the clinical spectrum (three case reports). Cephalalgia 2002;22:160-162.

20. Bahra A, May A, Goadsby PJ. Cluster headache: a prospective clinical study with diagnostic implications. Neurology 2002;58:354-361.

21. Leone M, Bussone G. Pathophysiology of trigeminal autonomic cephalalgias. Lancet Neurol 2009;8:755-764.

22. Narbone MC, Gangemi S, Abbate M. A case of SUNCT syndrome responsive to verapamil. Cephalalgia 2005;25:476-478.

23. Launer LJ, Terwindt GM, Ferrari MD. The prevalence and characteristics of migraine in a population-based cohort: the GEM study. Neurology 1999;53:537-542.

24. Russell MB, Rasmussen BK, Thorvaldsen P, et al. Prevalence and sexratio of the subtypes of migraine. Int J Epidemiol 1995;24:612-618. 